\title{
Red List assessments of East African chameleons: a case study of why we need experts
}

\author{
Angelique Hiarding, Krystal A. Tolley and Neil D. Burgess
}

\begin{abstract}
The IUCN Red List of Threatened Species uses geographical distribution as a key criterion in assessing the conservation status of species. Accurate knowledge of a species' distribution is therefore essential to ensure the correct categorization is applied. Here we compare the geographical distribution of 35 species of chameleons endemic to East Africa, using data from the Global Biodiversity Information Facility (GBIF) and data compiled by a taxonomic expert. Data screening showed $99.9 \%$ of GBIF records used outdated taxonomy and $20 \%$ had no locality coordinates. Conversely the expert dataset used $100 \%$ up-to-date taxonomy and only seven records (3\%) had no coordinates. Both datasets were used to generate range maps for each species, which were then used in preliminary Red List categorization. There was disparity in the categories of 10 species, with eight being assigned a lower threat category based on GBIF data compared with expert data, and the other two assigned a higher category. Our results suggest that before conducting desktop assessments of the threatened status of species, aggregated museum locality data should be vetted against current taxonomy and localities should be verified. We conclude that available online databases are not an adequate substitute for taxonomic experts in assessing the threatened status of species and that Red List assessments may be compromised unless this extra step of verification is carried out.
\end{abstract}

Keywords Conservation, expert knowledge, GBIF, IUCN Red List, museum specimen records, taxonomic data, threatened species

\footnotetext{
Angelique HJarding* (Corresponding author) and Neil D. Burgess $†$ Center for Macroecology, Evolution and Climate, Department of Biology, University of Copenhagen, Universitetsparken 15, DK-2100 Copenhagen, Denmark E-mail angel@hjarding.dk

Krystal A. Tolley $\ddagger$ Applied Biodiversity Division, South African National Biodiversity Institute, Cape Town, South Africa

*Current address: Department of Geography and Earth Sciences, University of North Carolina at Charlotte, 9201 University City Blvd., Charlotte, NC, USA 28223

†Also at: Conservation Science Program, WWF-US, Washington, DC, USA, and UNEP-WCMC, Cambridge, UK

¥Also at: Department of Botany and Zoology, Stellenbosch University, Stellenbosch, South Africa

Received 20 August 2013. Revision requested 16 September 2013.

Accepted 11 October 2013. First published online 10 July 2014.
}

\section{Introduction}

Secies distribution data may be used in assessing $\checkmark$ a species' risk of extinction (Mace \& Lande, 1991; Rodrigues et al., 2006; Baillie et al., 2008; Mace et al., 2008). The IUCN Red List of Threatened Species (IUCN, 2012) is a set of biodiversity data that are used to categorize species according to threats to their population, distribution and habitat (IUCN, 2001; IUCN Standards and Petitions Working Group, 2008). The Red List is used to inform policy and decision-making processes on national and international levels (Lamoreux et al., 2003; Mace \& Baillie, 2007; Hoffmann et al., 2008; Nicholson et al., 2012) and in biogeographical and biodiversity priority-setting analyses (e.g. Stuart et al., 2004; Grenyer et al., 2006; Isaac et al., 2007; Schipper et al., 2008).

Of the estimated $5 \pm 3$ million species, of which 1.5 million have been described scientifically (Costello et al., 2013), 63,837 (primarily vertebrates) are included on the 2012 IUCN Red List. Of the reptile species described, $38 \%(3,363)$ have been assessed and 802 species are categorized as threatened (IUCN, 2012). Approximately half of all chameleon species (the majority from Madagascar) have been assessed using the Red List criteria.

Red List assessments are typically completed at a workshop, where experts synthesize published and unpublished data within a formalized Species Information System. This approach is designed to overcome limitations in the availability of data, allows screening of existing data and compiles accumulated field experience that is not available in any published format (Huang et al., 2012).

According to estimates there may be 2-3 billion specimens in natural history collections (Duckworth et al., 1993; Ariño, 2010; Scoble, 2010), and in the past using these museum data for biodiversity research was challenging because information had to be compiled manually from the collections. However, many museums have digitized the information contained in their specimen collections and made it available through the Global Biodiversity Information Facility (GBIF, 2014), an electronic data portal that provides a single point of access to databases from hundreds of museums and private collections. Although a large amount of data is available through GBIF it is still only an estimated $3.2 \%$ of the primary biodiversity data records in collections. The reasons for this include a lack of funds for digitization, and political and social boundaries to data sharing. Consequently the records available through GBIF 


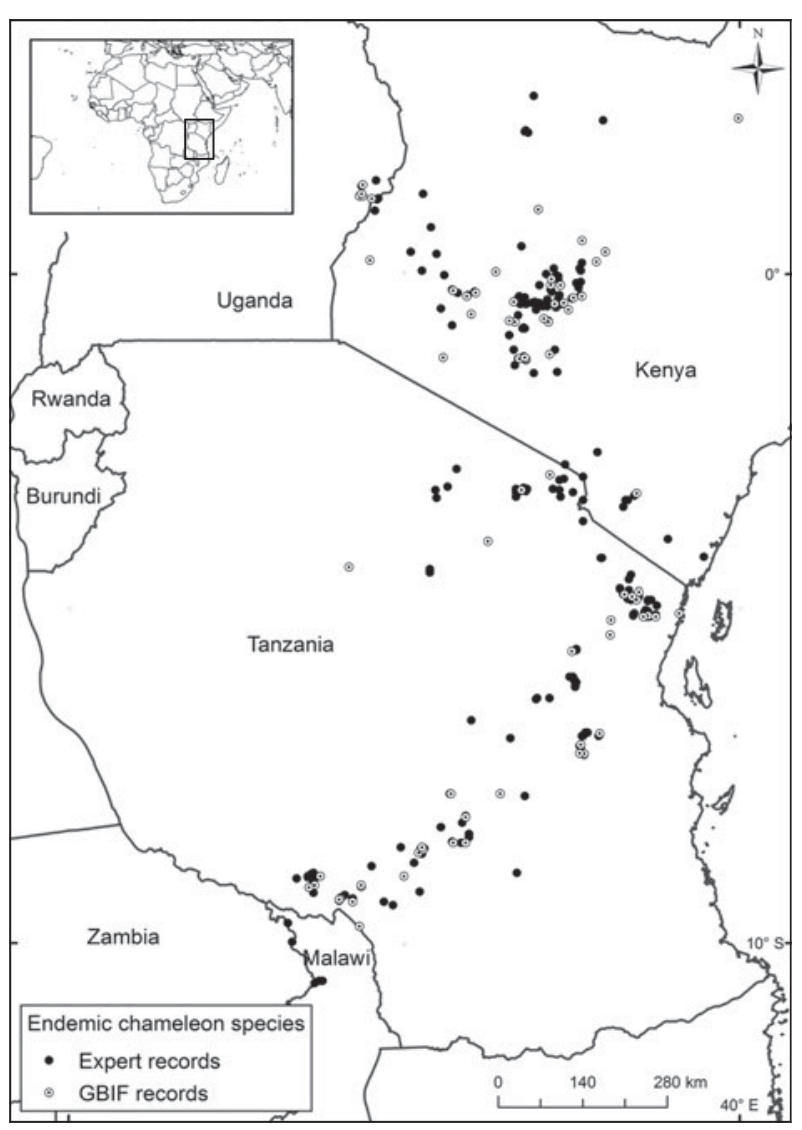

FIG. 1 Location of records of endemic East African chameleon species according to the expert (254 records) and GBIF (172 records) datasets. The rectangle on the inset indicates the location of the main map in Africa.

tend to be from larger institutions, mostly in the developed world.

The museum specimen data in GBIF have good temporal and geographical coverage (Boakes et al., 2010), and questionable records can be checked and details verified against the actual specimens. These data therefore have potential to support both biogeographical analyses and conservation decision-making but problems may arise as a result of inaccurate identification of specimens, outdated taxonomy, incorrect localities and poor transcribing of data from specimen labels into computerized systems (Ponder et al., 2001; Ariño, 2010; Newbold, 2010).

GBIF data are increasingly being used in studies of species richness and endemism (Foley et al., 2008; Désamoré et al., 2012; Ramirez-Villegas et al., 2012) and as presence data in species distribution modelling (Costa et al., 2010; Edvardsen et al., 2011; Vidal-Garcia \& Serio-Silva, 2011; Willis et al., 2012) but are not yet being used in Red List assessment workshops for animals, although herbarium records and databases such as Tropicos (2014) are used for Red List assessments of plants (Willis et al., 2003; Raimondo, 2009; Rivers et al., 2011).

Here we compare basic data quality attributes for 35 chameleon species endemic to Kenya and Tanzania (Fig. 1), using a GBIF dataset and expert data compiled from museum records, field research records and literature. Both datasets are then used to estimate the Extent of Occurrence (EOO, the area that encompasses all known occurrences) and Area of Occupancy (AOO, the area within the EOO that contains suitable habitat), which are the standard measures of distribution used in Red List assessments. The estimated EOO and AOO from each dataset are then used as the sole inputs to a hypothetical IUCN Red List assessment process, to compare similarities and differences in Red List categorization using each dataset. The full Red List assessment process would use a more complete set of data than range size but our aim was to illustrate differences that can arise when using different data sources.

\section{Methods}

We compiled a list of endemic chameleon species in Kenya and Tanzania, which was cross-checked by members of the IUCN Chameleon Specialist Group. Species assignments followed the most recent accepted taxonomy (Tilbury, 2010).

From this list a sample of 35 species was selected based on data availability. We created two datasets for the sample, one with expert data compiled and vetted by chameleon expert Colin Tilbury and the other with raw data obtained through GBIF. The expert dataset comprised 263 records assembled for the production of an atlas of African chameleons (Tilbury, 2010), which were sourced from museums, peerreviewed literature and unpublished field observations. The quality of locality information was checked by the expert and taxonomic data were updated. The second dataset comprised 2,304 museum records sourced from the GBIF data portal, using a query for records of chameleons in Kenya and Tanzania, which were then filtered to include only endemic species. These records were from six museums: Harvard Museum of Comparative Zoology, USA; Smithsonian Institution, USA; Ditsong Museum, South Africa; Bishop Museum, USA; Los Angeles County Museum of Natural History, USA; and California Academy of Sciences, USA. The expert dataset included data from 11 museums. The only museum included in both datasets was Ditsong Museum (Table 1).

Records from both datasets were cleaned according to criteria described in Chapman (2005), which included the removal of all records without geographical coordinates, all duplicate records and all specimens not identified to the species level. Scientific names were standardized against the currently accepted taxonomy (Table 2) and coordinates were checked in ArcGIS v. 10.1 (ESRI, Redlands, USA), with the removal of obvious outlier data points. Following this cleaning process 254 expert records $(93.3 \%$ of the original 
TABLE 1 Museums from which locality records for East African chameleons were obtained for the expert and GBIF datasets.

\begin{tabular}{|c|c|c|}
\hline \multirow[b]{2}{*}{ Museum } & \multicolumn{2}{|l|}{ Dataset } \\
\hline & Expert & GBIF \\
\hline Afrika Museum, The Netherlands & $\mathrm{x}$ & \\
\hline American Museum of Natural History, USA & $\mathrm{x}$ & \\
\hline Bishop Museum, USA & & $\mathrm{x}$ \\
\hline British Museum of Natural History, UK & $\mathrm{x}$ & \\
\hline Brussels Museum of Natural Sciences, Belgium & $\mathrm{x}$ & \\
\hline California Academy of Sciences, USA & & $\mathrm{x}$ \\
\hline Ditsong Museum, South Africa & $\mathrm{x}$ & $\mathrm{x}$ \\
\hline Los Angeles County Museum of Natural History, USA & & $\mathrm{x}$ \\
\hline Museum für Naturkunde, Germany & $\mathrm{x}$ & \\
\hline Museum of Comparative Zoology (Harvard University), USA & & $\mathrm{x}$ \\
\hline Naturhistorisches Museum Wien, Austria & $\mathrm{x}$ & \\
\hline Smithsonian Institution, USA & & $\mathrm{x}$ \\
\hline South African Museum, South Africa & $\mathrm{x}$ & \\
\hline Trento Museum of Natural Sciences, Italy & $\mathrm{x}$ & \\
\hline University of Dar es Salaam, Tanzania & $\mathrm{x}$ & \\
\hline Zoological Research Museum Alexander Koenig, Germany & $\mathrm{x}$ & \\
\hline
\end{tabular}

TABLE 2 Data quality and data cleaning requirements for the expert and GBIF databases, with numbers of records of raw data, cleaned data, requiring taxonomic update, for Chamaeleo species, with no geographical coordinates, and with no locality listed. Total cleaned data were the records used in the analysis.

\begin{tabular}{lllllcr}
\hline & Total & $\begin{array}{l}\text { Total } \\
\text { cleaned }\end{array}$ & $\begin{array}{l}\text { Requiring } \\
\text { taxonomic } \\
\text { update }\end{array}$ & $\begin{array}{l}\text { Chamaeleo } \\
\text { sp. }\end{array}$ & $\begin{array}{l}\text { No } \\
\text { geographical } \\
\text { coordinates }\end{array}$ & $\begin{array}{l}\text { No } \\
\text { locality } \\
\text { listed }\end{array}$ \\
\hline Expert & 263 & 254 & 0 & 0 & 7 & 0 \\
GBIF & 2304 & 172 & 2302 & 67 & 478 & 833 \\
\hline
\end{tabular}

${ }^{*}$ Many species in this genus have been reassigned to Kinyongia and Trioceros, but these changes are not reflected in the GBIF dataset.

expert dataset) and 172 GBIF records ( $7.5 \%$ of the original GBIF dataset) were retained for further analysis.

Once cleaned, distribution records for every species in each dataset were imported into ArcGIS, which was used to estimate the EOO and AOO. The EOO was estimated by creating convex hull polygons, using the point data records, to represent the potential habitat range for each species. The AOO was estimated using the guidelines provided by the IUCN Standards and Petitions Working Group (2008), using Jenness repeating shapes (Jenness, 2012) to create a fishnet grid of $4-\mathrm{km}^{2}$ hexagons. This is the scale recommended by the IUCN. The majority of the records did not have a precision estimate nor did they indicate the datum used when recording the locality coordinates. For mapping purposes it was assumed that WGS 84 was used as it is the default datum used in global positioning systems.

Criterion B of the Red List Categories and Criteria version 3.1 (geographical range in the form of EOO or AOO; IUCN, 2001) was applied to the calculated EOO/AOO for each species and used to categorize species as Critically Endangered, Endangered or Vulnerable. If there were not at least three locality records, which are required to estimate
EOO, the taxon was categorized as Data Deficient. No other criteria (e.g. fragmentation, number of locations, decline in habitat) were considered.

\section{Results}

Almost all of the records (99.9\%) in the GBIF dataset had taxonomy that did not match the species in our checklist, principally because the records accessed through GBIF were not updated to generic-level reassignments made within Chamaeleonidae during 2006-2013. In the GBIF dataset 478 of the records (21\%) had no geographical coordinates, whereas only seven records (3\%) in the expert dataset lacked coordinates. In addition, 833 records $(36 \%)$ in the GBIF dataset had no locality name, whereas all records in the expert dataset had a locality name. Records without locality but with coordinates were used in the analysis but it was not possible to verify the accuracy of these records.

Some records for Fischer's chameleon Kinyongia fischeri, Von Hohnel's chameleon Trioceros hoehnelii and Jackson's chameleon Trioceros jacksonii in the GBIF dataset were regarded as outliers because they were far outside known 
TABLE 3 Extent of occurrence (EOO) calculated using expert and GBIF datasets, area of overlap between the databases, and percentage overlap for each database, for 10 species of East African chameleon.

\begin{tabular}{|c|c|c|c|c|c|}
\hline Species & Expert EOO $\left(\mathrm{km}^{2}\right)$ & GBIF EOO $\left(\mathrm{km}^{2}\right)$ & Overlap $\left(\mathrm{km}^{2}\right)$ & \% overlap Expert & $\%$ overlap GBIF \\
\hline Kinyongia excubitor & 1,734 & 178 & 0 & 0 & 0 \\
\hline Kinyongia fischeri & 52 & 11,934 & 41 & 80 & 0 \\
\hline K. fischeri (no outlier) & 52 & 1,676 & 0 & 0 & 0 \\
\hline Kinyongia matschiei & 124 & 266 & 15 & 12 & 6 \\
\hline Kinyongia tavetana & 22,512 & 10,825 & 7,732 & 34 & 71 \\
\hline Trioceros deremensis & 14,260 & 14,909 & 13,080 & 92 & 88 \\
\hline Trioceros goetzei & 38,091 & 14,732 & 14,731 & 39 & 100 \\
\hline Trioceros hoehnelii & 50,467 & 116,134 & 38,589 & 76 & 33 \\
\hline T. hoehnelii (no outlier) & 50,467 & 51,978 & 38,355 & 76 & 74 \\
\hline Trioceros jacksonii & 58,632 & 995,151 & 58,632 & 100 & 6 \\
\hline T. jacksonii (no outlier) & 58,632 & 182,998 & 58,632 & 100 & 32 \\
\hline Trioceros tempeli & 10,390 & 11,707 & 6,894 & 66 & 59 \\
\hline Trioceros werneri & 40,516 & 7,890 & 5,769 & 14 & 73 \\
\hline
\end{tabular}

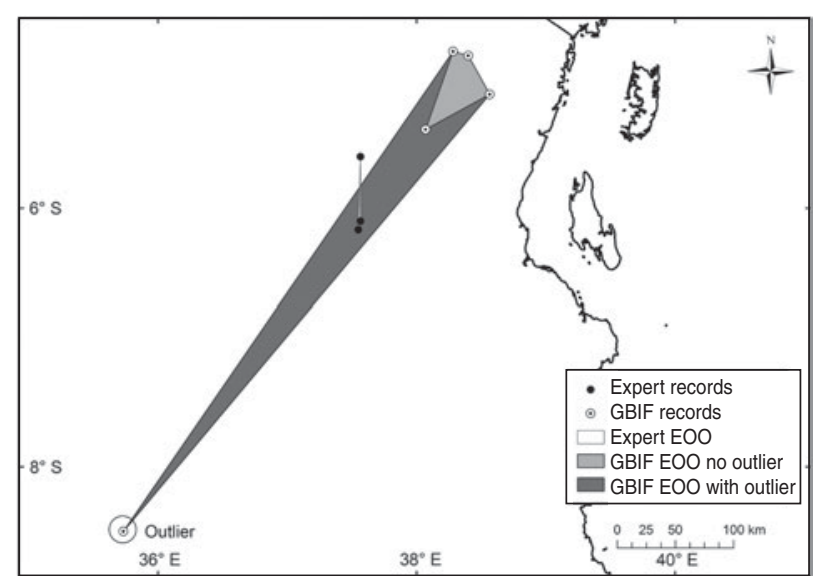

FIG. 2 Extent of occurrence (EOO) of Kinyongia fischeri in Tanzania, calculated using expert and GBIF datasets.

distributions. For $K$. fischeri the suspected outlier was $221 \mathrm{~km}$ from the nearest record in the expert dataset and $160 \mathrm{~km}$ from the nearest record in the GBIF dataset. There was $48 \mathrm{~km}$ between the nearest points in the GBIF and expert datasets (Fig. 2). In the GBIF dataset one record for T. hoehnelii was $218 \mathrm{~km}$ from other $T$. hoehnelii records and one record for T. jacksonii was $1,097 \mathrm{~km}$ from other T. jacksonii records. These two records probably resulted from misidentification.

In the expert dataset there were sufficient distribution records to estimate the EOO for 26 species and the AOO for 34 species (Table 3). The EOO could not be estimated for Kinyongia magomberae, K. uluguruensis, K. vanheygeni, K. vosseleri, Rhampholeon acuminatus, $R$. beraduccii, Trioceros marsabitensis, T. narraioca and T. ntunte because there were only one or two records for these species. In the GBIF dataset there were sufficient data to estimate the EOO for 10 species and the AOO for 19 species.

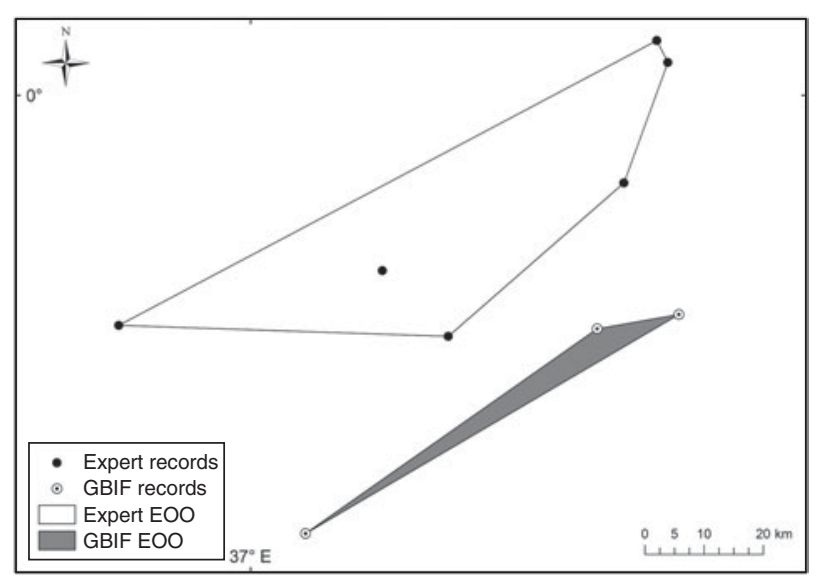

FIG. 3 EOO of Kinyongia excubitor in Kenya, calculated using expert and GBIF datasets.

The EOO for each species had varying degrees of overlap between the two datasets. For 10 of the 35 species there were overlaps in the ranges calculated using the GBIF and expert datasets (Table 3), with $T$. deremensis, T. tempeli and $T$. hoehnelii overlapping by $>50 \%$. For the remaining species there were large differences in the ranges calculated using the expert and GBIF datasets, which resulted in overlaps of $<50 \%$ and in some cases $0 \%$. When outliers were removed there were no range overlaps between the datasets for K. fischeri (Fig. 2) and K. excubitor (Fig. 3). The range for T. goetzei calculated using data from GBIF was located $100 \%$ within the range calculated using the expert dataset. The range for $T$. jacksonii calculated using the expert dataset was located $100 \%$ within the range calculated using the GBIF dataset.

Using the expert dataset 34 of the species were assigned a threat category, with only T. ntunte categorized as Data Deficient, whereas using the GBIF dataset 16 species (46\%) 
TABLE 4 Potential IUCN Red List categories that might be assigned to East African chameleon species, based on assessments using expert and GBIF datasets.

\begin{tabular}{lll}
\hline Species & Expert* & GBIF* \\
\hline Kinyongia asheorum & CR & DD \\
Kinyongia boehmei & CR & DD \\
Kinyongia excubitor & EN & EN \\
Kinyongia fischeri & CR & EN \\
Kinyongia magomberae & CR & DD \\
Kinyongia matschiei & EN & EN \\
Kinyongia multituberculata & EN & CR \\
Kinyongia oxyrhina & EN & CR \\
Kinyongia tavetana & EN & EN \\
Kinyongia tenuis & EN & CR \\
Kinyongia uluguruensis & CR & CR \\
Kinyongia uthmoelleri & EN & DD \\
Kinyongia vanheygeni & CR & DD \\
Kinyongia vosseleri & CR & CR \\
Rhampholeon acuminatus & CR & DD \\
Rhampholeon beraduccii & CR & DD \\
Rhampholeon moyeri & EN & DD \\
Rhampholeon spinosus & EN & CR \\
Rhampholeon temporalis & EN & DD \\
Rhampholeon uluguruensis & EN & DD \\
Rhampholeon viridis & EN & DD \\
Trioceros deremensis & EN & CR \\
Trioceros fuelleborni & EN & CR \\
Trioceros goetzei & EN & EN \\
Trioceros hoehnelii & EN & EN \\
Trioceros incornutus & EN jacksonii & EN \\
Trioceros laterispinis & EN & EN \\
Trioceros marsabitensis & CR & DD \\
Trioceros narraioca & CR & DD \\
Trioceros ntunte & DD & DD \\
Trioceros schubotzi & CR & DD \\
Trioceros sternfeldi & EN & DD \\
Trioceros werneri & & \\
\hline & EN & \\
\hline
\end{tabular}

${ }^{\star}$ CR, Critically Endangered; EN, Endangered; VU, Vulnerable; DD, Data Deficient

were categorized as Data Deficient. None of the species were categorized as Vulnerable, Near Threatened or Least Concern as all ranges were smaller than the minimum areas required for these categories.

The differences in geographical data for species in the two datasets resulted in some disparity in the Red List threat category assignments (Table 4). Only $10(29 \%)$ species had sufficiently similar EOO/AOO to be assigned the same Red List category for both datasets. For eight species the differences in the EOO/AOO between the datasets placed them in different threat categories under the Red List system, assuming additional criteria were met. Using the expert dataset these species would be categorized as Endangered, whereas using the GBIF dataset they would be categorized as Critically Endangered.

\section{Discussion}

These results show that distribution data for endemic East African chameleons vary substantially between expert and GBIF data sources, and this disparity would result in species being assigned to different IUCN Red List threat categories based on Criterion B. Less than $30 \%$ of the comparisons produced congruent results, with highly variable amounts of overlap between the ranges estimated using our two datasets.

Our results show that the quality of the raw GBIF dataset for East African chameleons is insufficient for direct use in assessments of IUCN threat status. There were two principal problems with the GBIF data. Firstly, most of the records obtained through GBIF used outdated taxonomy and did not reflect the numerous reassignments that have been made at the genus level. Secondly, 833 (36\%) of the GBIF records had no locality listed. Without expert review it is impossible to know if a locality record is correct.

Before being suitable for use in a Red List assessment, GBIF data will require basic geographical analysis such as checking for incorrect locality records and taxonomic updates. In comparison, our expert dataset was essentially ready for use in an IUCN Red-listing task. The perceived added value from including a large number of specimen records in the GBIF database was marginal because of the poor quality of the specimen records. Two other studies evaluating the fitness-for-use of GBIF data confirm that these problems also exist for other taxa, on a regional and global scale (Gaiji et al., 2013; Otegui et al., 2013).

The taxonomic shortcomings that we identified in the GBIF data are being addressed; for example taxonstand draws on a standardized database of plant names, and updates taxonomy automatically within the $R$ environment (Cayuela et al., 2012). Until additional resources are available to automate this process locality records should be vetted against current taxonomy and, if possible, verified by taxonomic experts. Following agreed standards for the georeferencing of localities data from museum specimen tags (Chapman \& Wieczorek, 2006) improves the usability of data but is expensive and time consuming.

Some of the differences between the datasets could also be attributed to biases, which are common in biodiversity research. For example, species records can be biased by expert knowledge (Ahrends et al., 2011b), accessibility (Freitag et al., 1998; Kadmon et al., 2004) and the popularity of a location for researchers (Reddy \& Dávalos, 2003; Ahrends et al., 2011a).

An important final question is whether either dataset provides sufficient coverage for accurate Red List assessments. In our view there were sufficient records to estimate the EOO/AOO for most species. However, differences between the two datasets could result in the assignment of species to different IUCN categories and this could have 
significant consequences as conservation decisions are often based on the IUCN Red List.

Despite the challenges faced when using GBIF data for Red List assessment, this public database is useful for filling knowledge gaps and facilitating the development of provisional maps of distribution, which can then be used in preliminary analyses such as those presented here, checked by experts, and used to identify potentially problematic issues in the estimation of EOO and AOO. Furthermore, large compilations of museum specimen data may be useful for macroecological analyses (Willis et al., 2012).

This exploratory exercise yielded a number of conclusions. Firstly, for East African chameleon species GBIF data are insufficient for Red List assessments because of problems with taxonomy and data outliers. Secondly, once GBIF data are vetted against current taxonomy and species localities are verified they are adequate to estimate the EOO for most species. Thirdly, gaps in GBIF data coverage may result in a species being assigned a higher category of threat in IUCN Red List assessments. We conclude that there is no substitute for the taxonomic expert in data compilation and analysis processes such as Red List assessments.

\section{Acknowledgements}

We thank Colin Tilbury for the use of his data in this study, Samy Gaiji and Vishwas Chavan from the Global Biodiversity Information Facility and Richard Jenkins from the IUCN Global Species Programme for support and comments, and the Chameleon Specialist Group for their assistance with verifying our species checklist.

\section{References}

Ahrends, A., Burgess, N.D., Gereau, R.E., Marchant, R., Bulling, M.T., Lovett, J.C. et al. (2011a) Funding begets biodiversity. Diversity and Distributions, 17, 191-200.

Ahrends, A., Rahbek, C., Bulling, M.T., Burgess, N.D., Platts, P.J., Lovett, J.C. et al. (2011b) Conservation and the botanist effect. Biological Conservation, 144, 131-140.

Ariño, A.H. (2010) Approaches to estimating the universe of natural history collections data. Biodiversity Informatics, 7, 81-92.

Baillie, J.E.M., Collen, B., Amin, R., Akcakaya, H.R., Butchart, S.H.M., Brummit T, N. et al. (2008) Toward monitoring global biodiversity. Conservation Letters, 1, 18-26.

Boakes, E.H., McGowan, P.J.K., Fuller, R.A., Chang-Qing, D., Clark, N.E., O'Connor, K. \& Mace, G.M. (2010) Distorted views of biodiversity: spatial and temporal bias in species occurrence data. PLoS Biology, 8(6), e1000385.

Cayuela, L., Granzow-de la Cerda, I., Albuquerque, F.S. \& Golicher, D.J. (2012) taxonstand: An R package for species names standardisation in vegetation databases. Methods in Ecology and Evolution, 3, 1078-1083.

Chapman, A.D. (2005) Principles and Methods of Data CleaningPrimary Species and Species-Occurrence Data, version 1.o. Report for the Global Biodiversity Information Facility, Copenhagen. Http:// www.gbif.org/resources/2833 [accessed 22 April 2014].

Chapman, A.D. \& Wieczorek, J. (eds) (2006) Guide to Best Practices for Georeferencing. Global Biodiversity Information Facility, Copenhagen. Http://www.gbif.org/resources/2809 [accessed 22 April 2014].

Costa, G.C., Nogueira, C., Machado, R.B. \& Colli, G.R. (2010) Sampling bias and the use of ecological niche modeling in conservation planning: a field evaluation in a biodiversity hotspot. Biodiversity and Conservation, 19, 883-899.

Costello, M.J., May, R.M. \& Stork, N.E. (2013) Can we name Earth's species before they go extinct? Science, 339, 413-416.

Désamoré, A., Laenen, B., González-Mancebo, J.-M., Jaén Molina, R., Bystriakova, N., Martinez-Klimova, E. et al. (2012) Inverted patterns of genetic diversity in continental and island populations of the heather Erica scoparia s.l. Journal of Biogeography, 39, 574-584.

Duckworth, W.D., Genoways, H.H. \& Rose, C.L. (1993) Preserving Natural Science Collections: Chronicle of Our Environmental Heritage. Heritage Preservation, Washington, DC, USA.

Edvarden, A., Bakkestuen, V. \& Halvorsen, R. (2011) A fine-grained spatial prediction model for the red-listed vascular plant Scorzonera humilis. Nordic Journal of Botany, 29, 495-504.

Foley, D.H., Weitzman, A.L., Miller, S.E., Faran, M.E., RuedA, L.M. \& Wilkerson, R.C. (2008) The value of georeferenced collection records for predicting patterns of mosquito species richness and endemism in the Neotropics. Ecological Entomology, 33, 12-23.

Freitag, S., Hobson, C., Biggs, H.C. \& van Jaarsveld, A.S. (1998) Testing for potential survey bias: the effect of roads, urban areas and nature reserves on a southern African mammal data set. Animal Conservation, 1, 119-127.

Gaiji, S., Chavan, V., Ariño, A.H., Otegui, J., Hobern, D., Sood, R. \& Robles, E. (2013) Content assessment of the primary biodiversity data published through GBIF network: status, challenges and potentials. Biodiversity Informatics, 8, 94-172.

GBIF (Global Biodiversity Information Facility) (2014) Free and Open Access to Biodiversity Data. Http://www.gbif.org [accessed 21 April 2014].

Grenyer, R., Orme, C.D.L., Jackson, S.F., Thomas, G.H., Davies, R.G., Davies, T.J. et al. (2006) Global distribution and conservation of rare and threatened vertebrates. Nature, 444, 93-96.

Hoffmann, M., Brooks, T.M., Da Fonseca, G.A.B., Gascon, C., Hawkins, A.F.A., James, R.E. et al. (2008) Conservation planning and the IUCN Red List. Endangered Species Research, 6, 113-125.

Huang, X., Hawkins, B.A., Lei, F., Miller, G.L., Favret, C., ZHANG, R. \& QIAO, G. (2012) Willing or unwilling to share primary biodiversity data: results and implications of an international survey. Conservation Letters, 5, 399-406.

Isaac, N.J.B., Turvey, S.T., Collen, B., Waterman, C. \& B Aillie, J.E.M. (2007) Mammals on the EDGE: conservation priorities based on threat and phylogeny. PLoS ONE, 2(3), e296.

IUCN (2001) IUCN Red List Categories and Criteria (version 3.1). IUCN Species Survival Commission, Gland, Switzerland, and Cambridge, UK.

IUCN (2012) IUCN Red List of Threatened Species v. 2012.2. Http:// www.iucnredlist.org [accessed 28 March 2013].

IUCN Standards and Petitions Working Group (2008) Guidelines for Using the IUCN Red List Categories and Criteria. Version 7.o. Prepared by the Standards and Petitions Working Group of the IUCN SSC Biodiversity Assessments Sub-Committee in August 2008.

Jenness, J. (2012) Repeating Shapes for ArcGIS. Http://www. jennessent.com/arcgis/repeat_shapes.htm [accessed 21 April 2014]. 
Kadmon, R., Farber, O. \& Danin, A. (2004) Effect of roadside bias on the accuracy of predictive maps produced by bioclimatic models. Ecological Applications, 14, 401-413.

Lamoreux, J., Akçakaya, H.R., Bennun, L., Collar, N.J., Boitani, L., Brackett, D. et al. (2003) Value of the IUCN Red List Trends in Ecology and Evolution, 18, 214-215.

Mace, G.M. \& Baillie, J.E.M. (2007) The 2010 biodiversity indicators: challenges for science and policy. Conservation Biology, 21, 1406-1413.

Mace, G.M., Collar, N.J., Gaston, K.J., Hilton-Taylor, C., AkÇaKaya, H.R., Leader-Williams, N. et al. (2008) Quantification of extinction risk: IUCN's system for classifying threatened species. Conservation Biology, 22, 1424-1442.

MaCE, G.M. \& LANDE, R. (1991) Assessing extinction threats: toward a reevaluation of IUCN threatened species categories. Conservation Biology, 5, 148-157.

Newbold, T. (2010) Applications and limitations of museum data for conservation and ecology, with particular attention to species distribution models. Progress in Physical Geography, 34, 3-22.

Nicholson, E., Collen, B., Barausse, A., Blanchard, J.L., Costelloe, B.T., Sullivan, K.M.E. et al. (2012) Making robust policy decisions using global biodiversity indicators. PLoS ONE, $7(7), \mathrm{e} 41128$.

Otegui, J., Ariño, A.H., Encinas, M. \& Pando, F. (2013) Assessing the primary data hosted by the Spanish node of the Global Biodiversity Information Facility (GBIF). PLoS ONE, 8(1), e55144.

Ponder, W.F., Carter, G.A., Flemons, P. \& Chapman, R.R. (2001) Evaluation of museum collection data for use in biodiversity assessment. Conservation Biology, 15, 648-657.

Raimondo, D. (2009) Red List of South African Plants. South African National Biodiversity Institute, Pretoria, South Africa.

Ramirez-Villegas, J., Jarvis, A. \& Touval, J. (2012) Analysis of threats to South American flora and its implications for conservation. Journal for Nature Conservation, 20, 337-348.

REDdy, S. \& DÁvalos, L.M. (2003) Geographical sampling bias and its implications for conservation priorities in Africa. Journal of Biogeography, 30, 1719-1727.

Rivers, M.C., Taylor, L., Brummitt, N.A., Meagher, T.R., Roberts, D.L. \& Nic Lughadha, E. (2011) How many herbarium specimens are needed to detect threatened species? Biological Conservation, 144, 2541-2547.

Rodrigues, A.S.L., Pilgrim, J.D., Lamoreux, J.F., Hoffmann, M. \& Brooks, T.M. (2006) The value of the IUCN Red List for conservation. Trends in Ecology and Evolution, 21, 71-76.

Schipper, J., Chanson, J.S., Chiozza, F., Cox, N.A., Hoffmann, M., Katariya, V. et al. (2008) The status of the world's land and marine mammals: diversity, threat, and knowledge.

Science, 322, 225-230.

Scoвle, M.J. (2010) Natural history collections digitisation: rationale and value. Biodiversity Informatics, $7,77-80$.

Stuart, S.N., Chanson, J.S., Cox, N.A., Young, B.E., Rodrigues, A.S.L., Fischman, D.L. \& Waller, R.W. (2004) Status and trends of amphibian declines and extinctions worldwide. Science, 306, 1783-1786.

Tilbury, C.R. (2010) Chameleons of Africa: An Atlas. Including the Chameleons of Europe, the Middle East and Asia. Edition Chimaira, Frankfurt, Germany.

Tropicos (2014) Http://www.tropicos.org/ [accessed 11 June 2014].

Vidal-García, F. \& Serio-Silva, J.C. (2011) Potential distribution of Mexican primates: modeling the ecological niche with the maximum entropy algorithm. Primates, 52, 261-270.

Willis, F., Moat, J. \& Paton, A. (2003) Defining a role for herbarium data in Red List assessments: a case study of Plectranthus from eastern and southern tropical Africa. Biodiversity and Conservation, $12,1537-1552$.

Willis, K.J., Jeffers, E.S., Tovar, C., Long, P.R., Caithness, N., SMIT, M.G.D. et al. (2012) Determining the ecological value of landscapes beyond protected areas. Biological Conservation, $147,3-12$.

\section{Biographical sketches}

Angelique HJarding is interested in biogeography, landscape ecology, urbanization and farmland preservation. KRYSTAL A. TOlley specializes in chameleon biogeography and systematics. NEIL D. BuRGESs is a conservation scientist specializing in African biological conservation issues, particularly in Eastern Africa. 